\title{
EFEITO DO BORO SOBRE OS TEORES DE PROTEÍNA E ATIVIDADE DA PEROXIDASE EM CALOS DE CANA-DE- AÇÚCAR (Saccharum spp. var NA56-79) IN VITRO
}

\author{
T.F. FUMIS ; O.G. BRASIL ${ }^{2}$ \\ ${ }^{\prime}$ Faculdade de Ciências-UNESP, C.P. 473, CEP: 17033-360 - Bauru,SP \\ ${ }^{2}$ Instituto de Biociências-UNESP, C.P. 505, CEP: 18618-000-Botucatu,SP
}

\begin{abstract}
RESUMO: Calos de cana-de-açúcar variedade NA56-79, foram desenvolvidos em meio de cultura contendo sais minerais acrescidos de hormonios e vitaminas. Apos a obtenção de quantidade suficiente de material, foram submetidos a três níveis diferentes de boro (omisso, $6,2 \mathrm{mg} / \mathrm{L}, 12,4 \mathrm{mg} / \mathrm{L}$ ). Foram analisados o teor protéco e a atividade da peroxidase. Os resultados mostraram que, em relação ao teor proteico, este foi menor na deficiência e maior em níveis mais elevados de boro. A variação da atividade da peroxidase mostrou um resultado inverso ao da proteina.
\end{abstract}

Descritores: cultura de tecidos, Saccharum spp.

\section{BORON EFECTS ON PROTEIN AND PEROXIDASE ACTIVITY IN SUGAR-CANE CALLUS (Saccharum spp var NA56-79)}

\begin{abstract}
ABSTRAT: Effects of boron were studied in sugar cane callus (Saccharum spp. var NA56-79) with the objective to find how this element changes biochemical parameters. Sugar cane callus were grown in media containing mineral nutrients, $60 \mathrm{mg} / \mathrm{L}$ of glicine, $60 \mathrm{mg} / \mathrm{L}$ arginine, $10 \%$ coconut water, $3 \mathrm{mg} / \mathrm{L} \mathrm{2}$-4-diclorofenoxiacetic acid, $20 \mathrm{~g} / \mathrm{L}$ sucrose, $9 \mathrm{~g} / \mathrm{L}$ agar and three boron concentrations $(0 \mathrm{mg} / \mathrm{L}, 6,2 \mathrm{mg} / \mathrm{L}$, and $12,4 \mathrm{mg} / \mathrm{L})$. Data showed that peroxidase activity raised and protein levels decreased when boron concentration raised.
\end{abstract}

Key Words: callus culture, Saccharum spp.

\section{INTRODUÇÃO}

No Brasil, a cana-de-açúcar (Saccharum spp.) é uma cultura economicamente importante, tanto na produção de açúcar como de álcool. Várias pesquisas vem sendo realizadas, com o objetivo de melhorar as colheitas, conteúdo de sacarose, tolerância a pesticida e resistência a doenças (CROCOMO et al. 1986). Os trabalhos pioneiros de HEINZ \& MEE (1969) e BARBA \& NICKELL (1969), demonstraram que as plantas de cana-de-açúcar poderiam ser regeneradas a partir de calos.

Um balanço nutricional é essencial para o crescimento e diferenciação das células e tecidos em meios de cultura, entre os constituintes desse meio, encontram-se os elementos minerais, que são importantes para a sobrevivência, tanto da planta no campo, quanto em cultura in vitro.

$O$ boro, sendo um micronutriente, $\hat{e}$ exigido em quantidades muito pequenas pela planta, mas a sua deficiência interfere em vários proces- sos, principalmente na síntese proteica e na atividade da peroxidase.

O objetivo do presente trabalho foi analisar o efeito de vários níveis de boro sobre a síntese proteica e a atividade da peroxidase, nos calos de cana-de-açúcar(Saccharum spp. var NA5679).

\section{MATERIAL E MÉTODOS}

Explantes obtidos de folhas mais internas dos colmos de cana-de-açúcar, foram inoculados em meio de cultura. Para se induzir a formação de calos usou-se como nutrientes minerais a proposição de MURASHIGE \& SKOOG (1962) adicionado de $60 \mathrm{mg} / \mathrm{L}$ de glicina, $60 \mathrm{mg} / \mathrm{L}$ de arginina, $100 \mathrm{mg} / \mathrm{L}$ de inositol, $10 \%$ água de coco, $3 \mathrm{mg} / \mathrm{L}$ de ácido 2-4-diclorofenoxiacético, 20 $\mathrm{g} / \mathrm{L}$ de sacarose e $9 \mathrm{~g} / \mathrm{L}$ de agar. $\mathrm{O} \mathrm{pH}$ foi ajustado a 5,8. Os meios de cultura inoculados foram colocados em câmaras de crescimento com temperatura controlada a $24^{\circ} \mathrm{C}$ e fotoperíodo de 12 
horas, por quatro semanas. Os calos obtidos, foram divididos em porções de $5 \mathrm{~mm}$ de diâmetro aproximado, e recolocados no mesmo meio descrito anteriormente alterado para tres níveis diferentes de boro( $(0 \mathrm{mg} / \mathrm{L}, 6,2 \mathrm{mg} / \mathrm{L}$, e $12,4 \mathrm{mg} / \mathrm{L})$. 0 experimento foi montado em placas de Petri de plástico, e mantidos a $24^{\circ} \mathrm{C}$ e fotoperíodo de 12 horas. As amostras foram coletadas em 4 épocas diferentes a intervalos de 7 dias.

A determinação quantitativa de proteínas foi feita pelo método de BRADFORD (1976) adaptado para calos de vegetais. A atividade da peroxidase (EC 1.11.1.7) foi determinada pelo método de ALLAIN et al. (1974), também adaptado para calos de vegetais.

\section{RESULTADOS E DISCUSSÃO}

O teor de proteína por grama de peso fresco diminuiu em relação ao crescimento de calos, provavelmente pelo aumento da quantidade de água absorvida pelas células (Fig. 1). Quando se considera os valores dentro dos tratamentos, verificamos que o aumento dos teores de boro leva a um aumento dos teores proteicos, mostrando uma influência positiva desse elemento no crescimento celular. ARTÉs et al. (1984), notaram que a síntese de proteínas foi afetada em plantas deficientes de boro. Estes autores fizeram referência a um menor conteúdo de proteínas totais, detectado quando o nível de boro na planta era baixo. MARSCHNER (1986) cita também que sob condições de deficiência de boro, o conteúdo proteico das folhas jovens diminuia. Há na literatura, resultados contraditórios com relação ao efeito do boro na síntese proteica. YIH \& CLARK (1965) e ESTEBAN et al. (1985), trabalhando com raízes de plantas de tomate $e$ MONTALVO-ZAPATA (1972), trabalhando com cana-de-açúcar, ambos deficientes de boro, detectaram aumento no teor proteico. BOWEN (1971), além do aumento do teor proteico encontrou uma redução nos níveis de RNA e nucleotídeos nos tecidos meristemáticos de cana-de-açúcar deficientes de boro, e em plantas com excesso desse microelemento constatou menor teor de proteínas, RNA e nucleotídeos solúveis, ou seja, um resultado contrário ao obtido em nosso experimento.

A atividade da peroxidase, aumentou durante as coletas, entretanto dentro dos tratamentos teve uma diminuição com o aumento da concentração de boro. A deficiência de boro, provoca aumento na atividade da enzima, segundo NASON et al. (1952) em folhas de tomateiro, ODHNOFF (1957) em raízes de feijoeiro, PARISH (1969) e ROBERTSON \& LOUGHMAN (1974), plântulas de Vicia faba, AGUIRRE et al. (1977) em folhas de feijoeiro e GOLDBACH \& AMBERGER (1986) em cultura de células de cenoura.

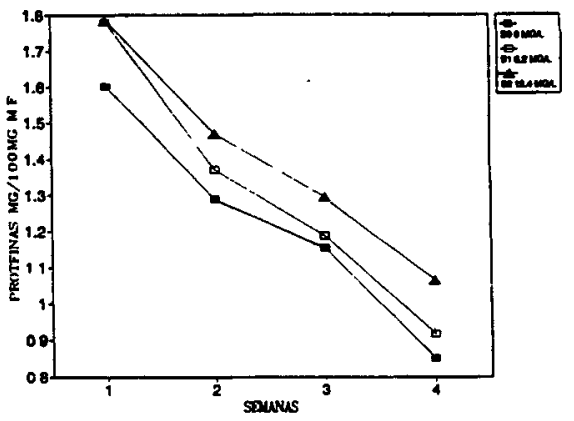

Figura 1 - Teor de proteínas expresso em $\mathrm{mg} / 100$ mg material fresco, de calos de canade-açúcar crescidos em diversas concentrações de boro.

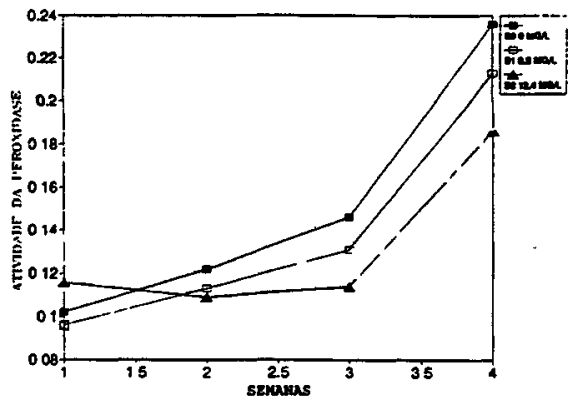

Figura 2 - Atividade da peroxidase expressa em micromol de peróxido de hidrogênio decomposto por minuto por miligrama de proteína em calos de cana-de-açúcar crescidos em diversas concentrações de boro.

A redução da atividade da enzima durante as épocas (Figura 2), foi também observada por BOWEN (1971) em tecidos de cana-de-açúcar, na presença de excesso de boro.

Os tratamentos no início do experimento (época 1), não apresentaram a mesma tendência das demais épocas, provavelmente, $o$ efeito residual do boro nos tecidos, poderia ter mascarado os resultados que foram evidenciados nas demais épocas, e deve-se considerar também, que no início, as células estavam se adaptando ao novo meio. 
Comparando-se a Figura $1 \mathrm{com}$ a Figura 2, nota-se que, enquanto os teores de proteínas diminuíram com $o$ decorrer do experimento, a atividade da peroxidase aumentou, o mesmo acontecendo entre os tratamentos. Enquanto o tratamento omisso em boro apresentou menores teores de proteínas, o tratamento submetido a nível mais elevado deste elemento, apresentou maior teor proteico, sendo verificado o contrário com a atividade da peroxidase. Através desses resultados, pode-se deduzir que o aumento da atividade da peroxidase entre as épocas, não foi devido ao aumento da proteína total.

\section{REFERÊNCIAS BIBLIOGRÁFICAS}

AGUIRRE, A.C.P.; DANTAS, J.P.; MORAES, M.F.; AMORIN, H.V. Teor de carboidratos e atividade da polifenoloxidase e peroxidase em plantas de Vigna sinensis var Pitiuba, cultivadas em soluçōes nutritivas de Hogland e Arnon completa e deficiente em boro. 0 Solo, Piracicaba, v.69, n.2, p.45-49, 1977.

ALLAIN, C.C; POON, L.S.; CHAN, C.S.G.; RICHMOND, W.; FU, P.C. Enzymatic determination of total serum cholesterol. Clinical Chemistry, New York, v.20, p.470-475, 1974.

ARTÉs, C.o.; RUIZ, R.C.; ZORNOZA, P.; COLLADO, G. A possible role for boron in higher plants. Journal of Plant Nutrition, New York, v.7, n.9, p.1341-1354, 1984.

BARBA, R.; NICKELL, L.G. Nutrition and organ differentiation in tissue culture of sugar cane, a monocoltyledon. Planta, Berlin, v.89, p.299-302, 1969.

BOWEN, J.E. Biochemical and physiological effects of boron in sugarcane. In: CONGRESS INTERNATIONAL OF SOCIETY SUGAR CANE TECHNOLOGISTS, 14., 1971, New Orleans. Proceedings... New Orleans: ISSCT, 1971. p.1113-1120.

BRADFORD, M.M. A rapid and sensitive method for the quantitation of microgram quantities of protein utilizing the principle of protein-dye binding Analytical Biochemistry, New York, v.72, p.248$254,1976$.

CROCOMO, O.J.; OCHOA-ALEJO, N.; GONÇALVES, C.H.R.P.; BACCHI, O.O.S. Development improved sugar cane varieties throught genetics engneering technics. In: CROCOMO, O.J.; SHARP, W.R.; EVANS, D.A.; BRAVO, J.E.; TAVARES, F.C.A.; PADDOCK, E.F. (Ed.) Biotechnology of plants and microorganisms. Columbus: Ohio State University, 1986. p.153-166.
ESTEBAN, R.M.; COLLADO, J.G.; ANDREU, F.J.L.; HERRERA, M.F. Effects of boron on soluble protein and sugar contents of tomatos roots. Plant and Soil, The Hague, v.88, p.149-151, 1985.

GOLDBACH, H.; AMBERGER, A. Influence of boron deficience on ${ }^{3} \mathrm{H}$-indole-3yl-acetic acid upptake and efflux in cell culture of Daucus carota L. Plant Growth Regulations, The Hague, v.4, p.81-86, 1986.

HEINZ, D.J.; MEE, G.W.P. Plant differentiation from callus tissue of Saccharum species. Crop Science, Madison, v.9, p.346-348, 1969.

MARSCHNER, H. Mineral nutrition of higher plants, New York: Academic Press, 1986. 674p.

MONTALVO-ZAPATA, P. Studies on the roles of boron in growth and sugar-transport processes of sugarcane. Journal of Agriculture of the University of Puerto Rico, Rio Piedras, v.57, p.9-23, 1972.

MURASHIGE, T.; SKOOG, F. A revised medium for rapid grow and bio assays with tabacco tissue cultures. Physiologia Plantarum, Copenhagen, v.15, p.473497, 1962.

NASON, A.; OLDEWURTEL, H.A.; PROPST, L.M. Role of micronutrient elements in the metabolism of higher plants. I. Changes in oxidative enzyme contitution of tomato leaves deficient in micronutrient elements. Archives of Biochemistry and Biophisic, v.38, p.1-13, 1952.

ODHNOFF, C. Boron deficiency and growth. Physiologia Plantarum, Copenhagen, v.10, p.9841000, 1957.

PARISH, R.W. Studies on the effect of calcium and boron on peroxidases of plant cell walls. Zeitschrift fur Pflanphysiologie, Berlin, v.60, p.211-216, 1969.

ROBERTSON, G.A.; LOUGHMAN, B.C. Response to boron deficiency; a comparison with responses produced by chemical methods of retarding root elongation. New Phytologist, London, v.73, p.821$832,1974$.

YIH, R.Y.; CLARK, H.F. Carbohydrate and protein content of boron-deficient tomato root tips in relation to anatomy and grow. Plant Physiology, Rockville, v.40, p.312-315, 1965 .

Entregue para publicação em 21.06.94

Aceito para publicação em 26.08 .94 